\title{
Organizational and technological parameters of facade works and influencing factors
}

\author{
Mukhammet Fakhratov and Ibrahim Fadhil* \\ Moscow State University of Civil Engineering, Yaroslavskoe shosse, 26, Moscow, 129337, Russia
}

\begin{abstract}
The article deals with the organizational and technological features of construction.

The organization of construction production for the installation of facade systems with an air gap during the construction of buildings is associated with coordination with general construction works. Often, construction management projects developed at the design stage are adjusted taking into account the current conditions. These changes can occur both before the start of work and during the production of work. The introduction of organizational and technological changes in the production process of work can lead to a significant decrease in technical and economic indicators. In this regard, it is relevant to resolve the issues of assessment and selection of effective organizational and technological solutions for the device of facade systems. The difficulty is the assessment of factors with different dimensions of quantitative and qualitative indicators. Installation of facade systems is a work performed in the open air, in connection with which there are factors that have a rather strong influence on the complexity of the work. In addition, as with any other construction work, it depends on the completion of other construction work. Another important feature of the organization of facade work is the orientation of the work front in the unfamiliar plane of the building. The study of this type of work is relevant and is of interest from a scientific point of view, not only in matters of constructive solutions for and organization of work and the use of appropriate machines and mechanisms. A well-grounded choice of technological equipment and the number and qualification of workers will increase the performance of work.
\end{abstract}

\section{Introduction}

The mechanism for making scientifically grounded decisions depends on the assessment of the impact of the decisions made on the technical and economic performance of the work. In modern conditions, in the preparation of construction production, it is no longer enough to have a lot of practical experience. Effective and well-grounded decisions can be made only on the basis of a variant design, taking into account the analysis of previously applied

\footnotetext{
* Corresponding author: eng.civil2004@gmail.com
} 
design and organizational and technological solutions, in order to reduce the labor intensity, cost and duration of construction. At the same time, the greatest difficulty is the assessment of factors with different dimensions of quantitative and qualitative indicators.

Factors affecting the organization and technology of construction work when performing facade work can be divided into several main groups:

1) initial factors (technical solutions adopted in the project documentation, requirements of the developer, customer, conditions for the supply of building materials, conditions for organizing a construction site);

2) direct determining factors (organizational and technological parameters of work, including the labor intensity of construction work, the number and qualification of workers, the number of seizures, the number of brigades);

3) indirectly influencing factors (natural and climatic conditions for the performance of work, the tightness of the construction site).

Depending on the degree of influence of certain factors, the organizational and technological parameters of the production of work also change $[1,2,5,6,8]$.

\section{Materials and methods}

The study of the issue was carried out on the basis of the analysis of theoretical data adopted in the organizational and technological documentation. During the study, a comparison of optimization methods was performed. Criteria assessment or application of a generalized indicator depends on the goals of the project and the tasks to be solved.

\section{Results}

To assess the impact of the organizational and technological parameters of the work on the main technical and economic indicators, the method of expert assessments was applied. The generalized opinion of experts obtained as a result of processing is accepted as a solution to the problem. Typical tasks solved using the method of expert assessments include: defining the goals and objectives of management with their ordering in order of importance; identification of alternative tasks with an assessment of their preferences; alternative allocation of resources for solving problems with an assessment of their preference; options for making decisions in a certain situation with an assessment of their preference. To solve the listed tasks, various types of expert assessments are used. In this work, we used a survey of specialists using a questionnaire. Expert judgment is a measurement process that can be defined as a procedure for comparing objects according to selected indicators. The objects of comparison in this work are the factors influencing the adoption of organizational and technological decisions. To describe experts in terms of assessing the quality of the solution to a problem, competence is one of the main characteristics. When assessing the weight characteristics of an expert, special attention is paid to the availability of an academic degree and production experience. To consider the influence of each factor on the main technical and economic indicators separately $[3,4,7,9]$. The main technical and economic indicators include:

-total labor intensity of work;

-specific labor intensity of work;

- standard construction duration;

- estimated duration of construction;

- the actual duration of construction;

-cost of work on the installation of facade systems;

- an indicator of the use of the area.

Requirements and recommendations of normative and technical documents for the production of works on the installation of facade systems can be divided into the following groups: according to the technical characteristics of the means of paving (scaffolding, front 
lifts and lifting platforms); requirements for the organization of a construction site (for the general case); technological requirements for installation; labor safety requirements. The customer's requirements are a set of technical, organizational and technological solutions, including the following: limiting the time frame for the production of work. The terms of delivery of components for facade systems are related to the fulfillment of contractual obligations by the supplier of materials, which may have the following features: timing and frequency of delivery of materials; volumes of supplied materials; organizational and technological aspects of contractual relations. Requirements related to obtaining a permit for the production of works include the following: coordination of the installation of paving equipment at the facility; time and space restrictions for the production of work.

Material and technical equipment of the contractor: quantitative and qualitative (appropriate qualifications) composition of the workforce; machines, mechanisms and means of paving necessary for the production of work.

Linkage of facade works with general construction (depending on the type of construction (construction, reconstruction, overhaul) is associated with the use of network planning, interconnection of work of subcontractors., Compliance with the terms and boundaries of work.

The basic labor intensity of the work is necessary to calculate the standard duration, but to calculate the estimated duration, the influence of various factors should be taken into account. The complexity of the installation of scaffolding equipment depends on the type of scaffold: scaffolding (frame, clamp), facade lifts and lifting platforms. The complexity of installation of facade systems depends on the constructive solution of the facade system (material of the protective and decorative screen, the metal consumption of the substructure, the complexity of the installation of the system and the number of heatinsulating layers), the scaffolds used, the geometric characteristics of the object (height, length along the perimeter), the complexity of the facade (the presence of protruding elements, broken surface and flatness of the facade, curvilinearity of the building in plan) and climatic conditions of work (air temperature, wind speed, the presence and type of precipitation). The complexity of the final work is determined by the complexity of the dismantling of the household town and the dismantling of the paving means.

One of the main issues in the development of organizational and technological documents is the choice of scaffolding tools. Currently, scaffolding, facade lifts and mast lifting platforms are used for the installation of facade systems. The choice of an option is carried out on the basis of a comparison of technical and economic characteristics. The choice of paving means depends on the design features of the object to be insulated. So, for example, front elevators, as a rule, are not advisable to use with a significant number of protruding elements of the facade (bay windows, elevator shafts outside the dimensions of buildings, cornices, etc.), with gable roofs, since after rearranging the elevator consoles, repair of their attachment points is required. The choice of means of paving largely determines all subsequent parameters of the production of work. Scaffolding is a versatile and safest means of paving, providing a wide scope of work and high performance in the installation of external insulation systems. The disadvantages include the time required for the installation and dismantling of scaffolding, which increases the overall labor intensity, occupation of the territory around the perimeter of the building, but at the same time, the danger zone is reduced as a result of the use of a protective mesh, which is especially important in tight urban conditions. The disadvantages of scaffolding can also be attributed to the height of application (recommended up to $60 \mathrm{~m}$ ) and the safety of the construction site, which is being reconstructed or overhauled without resettling the residents. Facade lifts are the most mobile type of mobile scaffolds for working on building facades. The advantage over scaffolding is the speed of installation and the ability to move along the height of the building up to $150 \mathrm{~m}$. At the same time, the division into grips is clearly traced, 
the width of which is equal to the width of the hoist. The scope of work is directly proportional to the number of platforms. The disadvantages include a great dependence on weather conditions (rain, snow, wind), the need for a flat roof, or installation inside a building and the presence of a danger zone under the work site. Working lifting platforms allow to carry out facade work at a height of up to $150 \mathrm{~m}$ with a simultaneous front along the width of the facade up to $40 \mathrm{~m}$, with a lifting capacity of up to 3.5 tons, for a given platform length. The advantages also include the high speed of assembly of the scaffold. The disadvantages include the high rental cost and dependence on weather conditions, and the presence of a dangerous zone under the work site and, accordingly, the safety of work at height. Structures of facade systems have a wide assortment, and the experience of unsuccessful solutions for the use of systems leads to a constant change and improvement of their design features. The development of new systems leads not only to obtaining the necessary characteristics, but also to a change in the installation technology, in particular labor intensity. Despite the large number of solutions presented, groups can be distinguished among them according to certain criteria. In addition to the well-known methods of industrial and building insulation of external walls, there are design solutions that increase the technical and economic indicators of the device of external insulation systems. The analysis of the organization of construction production when installing hinged facade systems allows us to conclude that, depending on the choice of certain means of paving, three basic basic options for the production of work are possible. The formation of basic options occurs in the following stages:

1) determination of the possibility of using a specific type of paving means;

2) determination of the rationality of the use of paving means;

3) the choice of means of paving;

4) determination of the labor intensity of the production of work;

5) determination of the number of captures, the direction of development of flows and the introduction of organizational and technological restrictions;

6) determination of the number of workers.

Importance during execution of facade work is the nature of the wall surface. For these purposes, it is necessary to introduce the complexity factor of the facade. The complexity factor of the facade is taken depending on the complexity group, while if there are characteristics of several groups, then the complexity factor of these groups is summed up, balconies and air conditioners are the protruding elements of the building. Various additional building elements on the facade of buildings increase the complexity. During assembling a facade on buildings with special features, the complexity of the work is adjusted taking into account the total complexity factor of these groups.

The standard duration of the construction and installation work is determined on the basis of regulatory documents. In this case, it is necessary to take into account the influence of the local climatic conditions of the work. According to the analysis of the data, the climatic conditions affecting labor intensity include:

1) outdoor temperature;

2) atmospheric precipitation;

3) wind effects.

Atmospheric precipitation in the form of rain, snow can also have a significant impact on the production of work. Work from front lifts and lifting platforms is suspended in the presence of such conditions. Wind influences affect the labor intensity of installation of the facade system, depending on the means of paving used, and the construction area in accordance with the regulatory and technical documents. Work is prohibited at a wind speed of $10 \mathrm{~m} / \mathrm{s}$ for facade lifts and $15 \mathrm{~m} / \mathrm{s}$ for lifting platforms. When working from scaffolding with the use of a protective mesh (or other elements of the fence), with an increase in wind speed, the effect of "sailing" occurs. 
The tightness of the construction site is a dimensionless value and is characterized by the coefficient of tightness, which is equal to the indicator of the use of the area of the master plan for temporary buildings, on-site warehouses, scaffolding, etc. The constraint coefficient affects the organization of the construction site: the size of on-site warehouses, the number of temporary buildings, etc. The placement of on-site warehouses should be made taking into account the location of access roads and entrances from the main transport routes to the places of acceptance and unloading of materials. On-site warehouses of prefabricated elements, enlarged structures, materials, semi-finished products, etc. should be located in the crane's operating area. The width of a mechanized on-site warehouse is set depending on the parameters of loading and unloading machines and usually does not exceed $10 \mathrm{~m}$. tower crane). When placing warehouses, one should be guided by the decisions made in technological maps and workflow schemes. In open warehouses, when storing products, structures and semi-finished products, it is necessary to provide longitudinal and transverse aisles. The surface of the site for the storage of materials, structures, products and equipment must be planned and compacted. In soft soils, the surface of the site can be compacted with gravel or lined with road slabs on a sandy base. Materials, structures, products and equipment should be placed in accordance with the requirements of standards, intersectoral rules for labor protection during loading and unloading and placement of goods, or the specifications of manufacturers. On-site warehouses must be provided for the storage of heat-insulating materials, light-section metal from thin sheet steel. Small parts, components must be stored in closed-type material and technical warehouses. At the same time, two main options can be distinguished that characterize the tightness of the production of work: urban cramped conditions and free conditions. The tightness of the construction site is characterized by the tightness coefficient, which affects the size of the household town. Based on the existing conditions, the intensity of construction production is formed, which includes: the number of workers, the daily production of materials, etc. Another characteristic of the constraint of work is the use of paving means. When performing work in inconvenient and cramped conditions, appropriate coefficients are applied to the labor costs $[15,16]$.

In the organization of construction production, the duration of construction is distinguished: standard, calculated and actual. The standard duration is determined in the organizational and technological documentation for the specific labor intensity adopted in accordance with the regulatory and technical documents and local conditions $[11,12,13]$. The actual duration is determined at the end of the work. The main factors affecting this value are the financial support of construction, climatic conditions for the production of work and other unaccounted factors $[17,18.19 .20]$.

Despite the fact that the process of mastering advanced technologies for thermal protection of buildings began more than 20 years ago, the problem of manufacturing defects when performing work on insulation and finishing of facades, as before, remains one of the most important problems of modern construction. Moreover, if at the initial stage of introducing thermal insulation systems for external enclosing structures into domestic construction practice, mass defects could be attributed to imperfect technologies or a lack of professionalism of installers, today the unsatisfactory quality of facades is the result of a series of mistakes made by participants in the architectural and construction process at various stages of project. This is largely due to the developing and immature construction market, in which dozens of firms have appeared that supply systems for protective and decorative finishing of buildings, and contractors that provide installation services, among which there are many companies, the main principle of production and commercial activity of which is obtaining profits by any means, including by saving on high-quality building materials, non-observance of production technology, low level of organization of construction production. The result of this approach is a low warranty for the work 
performed and frequent repairs. Generalization and reduction of the number of errors in the installation of hinged facade systems is an important element of organizational and technological design, since elements of the substructure of the facade system are a potential source of danger and form the danger zone of the building, which is unacceptable especially on busy city streets.

A review of the experience of using façade systems has shown that in recent years the curtain wall market in Russia has been growing at a faster pace than the plaster façade market. Currently, the volume of installation of ventilated facades exceeds the volume of installation of "wet" facade systems. In the next few years, the curtain wall segment will develop more rapidly than the market for plaster thermal insulation systems. Existing normative and technical documents give separate requirements for constructive solutions and technical characteristics of facade systems and general requirements for the technology and organization of work. Existing regulatory and technical documents do not fully disclose the features of organizational and technological design and production of work, in particular, the design of a building master plan for the installation of hinged facade systems and the design of a calendar plan. Indicators for the specified nomenclature as the initial data in the design assignment, it is impossible to accurately achieve the required level of indicators, since some of them will be higher, others below the specified ones. A high assessment of quality can be given to design products that are at the level of the basic values of these indicators or exceed them, provided that technological processes and equipment are used that correspond to the latest achievements of science and technology, progressive products and materials, and advanced methods of organizing production.

In modern conditions, the development of an organizational and technological scheme precedes the development of organizational and technological documents and is necessary to select the most effective option for the production of work. Another purpose of organizational and technological design is to give flexibility to the organization of construction. In the developing construction market, this feature is gaining its relevance, because often, when the participants in the construction process interact, failure to fulfill obligations by one of them entails changes in the general scheme of organization of construction production and technological schemes for installing facade systems, it acquires a special function of a backup option and is an effective way of making operational changes into the current construction industry. At this stage, decisions are made on the choice of means of mechanization, the sequence (stages) of work, the formation of teams of workers, ensuring the safety of work and other organizational and technological parameters. The decision is made on the basis of studying the working project, analogs, as a result of studying local conditions, after performing calculations and preliminary studies, etc. The volume and depth of preliminary studies depend on the contractor's own experience. The result of the analysis of the information obtained is the production schemes of work with varying degrees of detail on the device of hinged facade systems. In the normative and technical and methodological documentation on the organization and technology of construction production, it is indicated that organizational and technological schemes are drawn up, as a rule, when developing projects for organizing construction

\section{Conclusion}

Thus, the analysis of the influencing factors showed that:

-the determining factors in the organization of work are the geometric characteristics of the object, financial support for the production of work and the choice of appropriate organizational and technological parameters for the production of work;

- one of the most important issues in the design of works is the choice of the necessary means of paving; 
- when choosing means of paving, the comparison is made in terms of the laboriousness of installation (dismantling), the cost of rent (acquisition), safety of work;

- it is necessary to take into account the climatic conditions for the production of work, since this can not only increase the labor intensity, but also suspend the production of work completely;

- the cost price of work with the use of scaffolding is significantly higher than with the use of front lifts. The cost price decreases with an increase in the number of workers and captures;

- the use of front elevators is limited by climatic conditions and their inefficiency at low-height facilities;

- the use of mast lifting platforms is advisable for large volumes of work and is limited by the cost of their rental.

The studied features of the performance of facade work can be taken into account when organizing construction processes and will increase the performance of work. Evaluating design solutions, they are usually divided into external and internal parameters that characterize the system under consideration. External indicators are requirements indicators that characterize the customer's conditions, the requirements of design organizations and the imposed requirements of regulatory and technical and directive documents. The internal indicators include the organizational and technological parameters of the production of work. To make organizational and technological decisions based on the technical and economic indicators of the basic options for the production of work, it is necessary to take into account the criteria of minimum labor intensity, duration, cost and the criterion of adaptation to existing conditions that regulate the directive indicators. The effectiveness of organizational and technological solutions for the installation of facade systems during the overhaul of residential buildings can be carried out by calculating a comprehensive performance indicator, consisting of an assessment of the quality of collection and analysis of initial, a comprehensive assessment of the system of influencing factors, the effectiveness of the formation of basic options and the effectiveness of the choice of organizational and technological parameters production of works.

\section{References}

1. Lapidus A., Abramov I. Implementing large-scale construction projects through application of the systematic and integrated method XXIst International Scientific Conference on Advanced in Civil Engineering: Construction - The Formation of Living Environment, FORM 2018. "IOP Conference Series: Materials Science and Engineering" 2018. P. 062002.

2. Lapidus A.A., Yves N. Integrated quality index of organizational and technological solutions for implementation of burundian capital master plan Materials Science Forum. 2018. T. 931 MSF. P. 1295-1300.

3. Kuzhin M.F., Grezeva A.S., Kochergina O.D. Increasing the level of construction safety by using the protective and catching systems Materials Science Forum. 2018. T. 931 MSF. C. 1281-1285.

4. Topchy D.V., Lapidus A.A. Construction supervision at the facilities renovation Topical Problems of Architecture, Civil Engineering and Environmental Economics (TPACEE 2018) electronic edition. Ser. "E3S Web of Conferences" 2019. P. 08044.

5. Lapidus A., Dmitry T. Formation of methods for assessing the effectiveness of industrial areas' renovation projects IOP Conference Series: Materials Science and Engineering 3. Ser. "3rd World Multidisciplinary Civil Engineering, Architecture, Urban Planning Symposium, WMCAUS 2018 - Session 1" 2019. P. 022034. 
6. Lapidus A., Shesterikova Y. Mathematical model for assessing the high-rise apartment buildings complex quality E3S Web of Conferences 2019. P. 02025.

7. Lapidus A.., Abramov I. Systemic integrated approach to evaluating the resource potential of a construction company as a bidder IOP Conference Series: Materials Science and Engineering 3rd World Multidisciplinary Civil Engineering, Architecture, Urban Planning Symposium (WMCAUS 2018). 2019. P. 052079.

8. Sinenko S.A., Ginzburg V.M., Sapozhnikov V.N., Kagan P.B., Ginzburg A.V. Automation of org. and technolog. design in construction: Textbook.- Saratov: Higher education, 2019. -235p.

9. Kuzhin M.F. Evaluation and selection of organizational and technological parameters for production of works when constructing mounted faade systems with air gap Industrial and civil construction. 2012. No. 9. S. 61-62.

10. Abramov I, Lapidus A. Systemic integrated method for assessing factors affecting construction timelines Collected at: International Scientific Conference Environmental Science for Construction Industry - ESCI 2018 Ser. "MATEC Web of Conferences" 2018.S. 05033.

11. Oleinik P.P. The choice of the rational relationship of the method and form of organization of construction Industrial and civil construction. 2019.No 6.P. 46-50.

12. Pakhomova L.A., Oleinik P.P. Selection and assessment of parameters for certification of work places sout (special assessment of working conditions) Technology and organization of construction production. 2019.No 1. S. 49-52.

13. Oleinik P., Yurgaytis A., Voronina G., Makarenko A. Methods for the formation and optimization of calendar plans for construction companies Collected: MATEC Web of Conferences 2018.S. 05037.

14. Zhadanovsky B.V., Erzhokova E.S., Gorshkova E.A. Stream method as a way of organizing the construction of System Technologies. 2018. No. 3 (28). S. 136-140.

15. Fahratov M.A. Source materials and corrective ingredients for lightweight expanded clay aggregate gravel manufacturing Components of Scientific and Technological Progress. 2017. № 1 (31). C. 14-16.

16. Lapidus A.A., Tolstova K.S., Topchiy D.V. Formation of groups of parameters affecting the criterion of admissibility of combining processes in the production of finishing works Science and business: development paths. 2018.No 6 (84). S. 18-22.

17. Solomatina M.I. Study of the influence of destabilizing factors on the reliability of production processes. In the collection: Days of student science. Collection of reports of a scientific and technical conference based on the results of research work by students of the Institute of Construction and Architecture. 2019.S. 1299-1301.

18. Liu, J., \& Lu, M. (2020). Synchronized optimization of various management-function schedules in a multiproject environment: Case study of planning steel girder fabrication projects in bridge construction. Journal of Construction Engineering and Management, 146(5) doi:10.1061/(ASCE)CO.1943-7862.0001813.

19. Arashpour, M., Kamat, V., Bai, Y., Wakefield, R., \& Abbasi, B. (2018). Optimization modeling of multi-skilled resources in prefabrication: Theorizing cost analysis of process integration in off-site construction. Automation in Construction, 95, 1-9. doi:10.1016/j.autcon.2018.07.027.

20. Sun, Q., Li, D., \& Ren, Y. (2018). Study of redundancy and variance based P-cycle construction algorithm. Tiedao Xuebao/Journal of the China Railway Society, 40(12), 101-107. doi:10.3969/j.issn.1001-8360.2018.12.013 